\title{
INSERÇÃO DOS EGRESSOS DO ENSINO TÉCNICO AO MERCADO DE TRABALHO DO SETOR MOVELEIRO
}

Paulo Roberto SPINATO ${ }^{1}$

Sylvia MESSER ${ }^{2}$

Claudionor Guedes LAIMER ${ }^{3}$

\author{
${ }^{1}$ Mestre em Gestão Estratégica de Negócios pela Universidad Nacional de Missiones (UNAM) \\ Professor e coordenador de curso da Escola Técnica Estadual 25 de Julho, Ijuí, RS, Brasil. \\ E-mail: adm.spinato@gmail.com \\ ${ }^{2}$ Mestre em Educação nas Ciências pela Universidade Regional do Noroeste do Estado do Rio Grande do Sul (UNIJUI) \\ Professora do Instituto Federal Farroupilha - Campus Panambi, RS, Brasil. \\ E-mail: sylviamesser@pb.iffarroupilha.edu.br \\ ${ }^{3}$ Doutor em Administração pela Universidade do Vale do Rio dos Sinos (UNISINOS) \\ Professor e pesquisador do Mestrado em Administração da Faculdade Meridional (IMED), Passo Fundo, RS, Brasil. \\ E-mail: laimer@imed.edu.br
}

Recebido em: 15/02/2016 - Aprovado em: 14/10/2016 - Disponibilizado em: 18/12/2016

\begin{abstract}
RESUMO:
A recente reforma curricular tem como pressuposto básico a educação profissional integrada ao ensino médio. Desse modo, este artigo tem como objetivo analisar a inserção dos egressos do ensino técnico ao mercado de trabalho, a partir do sistema de avaliação implantado com a reforma curricular. Com isso, realizou-se uma pesquisa exploratória, com base em um estudo de caso de uma escola técnica. A coleta de dados foi realizada através de observações, documentos e entrevistas em profundidade com estudantes do curso técnico em móveis e com o gerente de produção de uma empresa moveleira. Como resultado, contatou-se que o gerente de produção teve dois estudantes aptos como seus estagiários, sendo um deles com um baixo nível de aptidão (50\% a 60\%) e outro com alto nível de aptidão (90\% a 100\%). Embora o atual sistema de avaliação não permita uma pontuação final (apenas uma relação de aptidão ou não), observou-se que os estudantes apresentam diferentes tipos e níveis de competências e habilidades adquiridas e/ou desenvolvidas durante a sua formação.
\end{abstract}

Palavras-chave: Competências. Habilidades.Sistema de avaliação. Mercado de trabalho. Setor moveleiro.

\section{INSERTION OF GRADUATES OF TECHNICAL EDUCATION TO THE LABOR MARKET OF FURNITURE SECTOR}

\begin{abstract}
:
The recent curriculum reform has the basic assumption of the professional education integrated high school. Thus, this article aims to analyze the insertion of graduates of technical education to the labor market, from the evaluation system implemented with the curriculum reform. With that, there was an exploratory research, based on a case study of a technical school. Data collection was conducted through observations, documents and interviews with students of technical courses in mobile and the production manager for a furniture company. As a result, it was found that the production manager had two students fit as his trainees, including one with a low aptitude level (50\% to 60\%) and a high aptitude level (90\% to 100\%). Although the current evaluation system does not allow a final score (only one aptitude relationship or not), it was observed that students have different types and levels of skills and competences acquired and/or developed during their training.
\end{abstract}

Keywords: Competencies. Skills. Evaluation system. Job market. Furniture sector. 


\section{INTRODUÇÃO}

As mudanças sociais, políticas, econômicas e tecnológicas ocorridas a partir da década de 1990repercutiram intensamente na sociedade em geral, marcando uma nova era, com avanços nas tecnologias de informação e comunicação (TICs). Esses avanços tecnológicos têm influenciado $\mathrm{O}$ mercado de trabalho (CASTELLS, 2003), especialmente, em função das inovações em produtos e processos, trazendo novos desafios à educação profissional.

Neste contexto, ocorreu a promulgação da Lei de Diretrizes e Bases da Educação Nacional, que estabeleceu as diretrizes e bases da educação, reorganizando sistema educacional brasileiro (BRASIL, 1996). Desse modo, a legislação definiu os fundamentos da educação profissional, a partir do ensino técnico em escolas técnicas e profissionais. Assim, o ensino técnico passou a ter espaço como educação profissional, buscando uma identidade para o ensino médio, a partir de um modelo de desenvolvimento econômico e tecnológico.

Por outro lado, a reforma no ensino médio gerou inúmeros debates e discussões sobre o melhor modelo a ser seguido. Nos mais diferentes estados brasileiros, os debates e discussões suscitaram inúmeras proposta de organização curricular, bem como o seu impacto na reestruturação das escolas de ensino médio e/ou técnico, até então vigentes.
Assim, constantes mudanças enfrentadas pela sociedade têm sido ampliadas por períodos instáveis e complexos (BOWDITCH; BUONO, 2004), que geram incertezas e expectativas em relação à implantação, manutenção e continuidade da educação profissional. Portanto, pensar no ensino técnico como proposta de reestruturação curricular do ensino médioimplica em compreender as exigências do mercado de trabalho.

Desta forma, tem sido importante a realização de estudos e pesquisas que busquem compreender como os estudantes e os empresários percebem a educação profissional, a partir do sistema de avaliação das aptidões adquiridas e/ou desenvolvidas em escola técnica? Com o propósito de oferecer resposta a pergunta, este estudo tem como objetivo analisar a inserção dos egressos do ensino técnico ao mercado de trabalho, a partir do sistema de avaliação implantado com a reforma curricular.

Para desenvolver esse estudo optou-se por definir como uma unidade de análise, uma escola técnica, a partir da acessibilidade dos dados. Desse modo, a escolha do caso a ser estudado se justifica pelas características da organização (i.e.,escola técnica que realizou reforma curricular) e por ter egressos que atuam em empresas locais. 
REFORMA CURRICULAR DO ENSINO MÉDIO

O ensino médio brasileiro passou por uma série de mudanças estruturais desde a Constituição Federal de 1988, que apresentou importantes alterações que visavam a progressiva extensão da obrigatoriedade e gratuidade do ensino médio. Entretanto, as mudanças continuaram durante as décadas seguintes, em especial, com a alteração do texto constitucional com a Emenda Constitucional 14 de 1996.

Naquele período foi promulgada a lei $\mathrm{n}^{\circ} 9.394$ em 20 de dezembro de 1996, denominado de LDB, criando uma identidade ao ensino médio e, proporcionando, facultativamente, uma formação profissional (BRASIL, 1996). Com o passar dos anos essas disposições legais foram sofrendo alterações, que, posteriormente, com o advento da lei $n^{\circ} 11.741$ de 16 de julho de 2008, definiu a atuação do ensino médio e da educação profissional.

Neste sentido, a educação profissional passa ser desenvolvida nos próprios estabelecimentos de ensino médio ou em cooperação com as instituições especializadas em educação profissional (BRASIL, 2008). Além disso, a educação profissional pode ser articulada com o ensino médio, de forma integrada ou concomitante ao ingressante ou egresso do ensino médio na mesma instituição ou em instituições diferentes.
Dessa forma, somente os cursos técnicos e superiores fazem parte da regulamentação da educação profissional e sua certificação deve ser determinada pela formação, avaliação por competência e por área profissional. Com isso, devem ser flexíveis para atender às demandas do mercado de trabalho, da sociedade e dos próprios cidadãos (CNE, 2001).

\section{SISTEMA DE AVALIAÇÃO}

A educação profissional passou a contar com um sistema de avaliação do currículo por competências, que foi implantado nas escolas técnicas. Essa avaliação certamente é um dos maiores desafios da prática pedagógica, pelo fato de ser muito relevante para professores, estudantes e mercado de trabalho. Pois, tem como propósito oferecer uma melhor noção quantificada do ensino e da aprendizagem dos estudantes.

O sistema de avaliação no ensino técnico profissionalizante conceitua seus estudantes como NÃO APTOS ou APTOS. Assim, considera-se NÃO APTO aquele estudante que tiver o desenvolvimento das competências e habilidades propostas nos planos pedagógicos de cada curso inferior a $50 \%$, ao passo que APTO aquele que tiver esse índice igual ou maior a 50\%, sem maiores distinções no intervalo de 50 a $100 \%$. 
Por outro lado, o mercado de trabalho está cada vez mais exigente e busca profissionais diferenciados e, por isso, faz-se necessário conhecer e analisar com profundidade a formação profissional. De tal modo, que a utilização de forma diferenciadas de avaliação devem ser implementadas, buscando a partir de instrumentos úteis, o direcionamento da prática pedagógica.

Neste sentido, a competência é a capacidade de mobilizar diversos recursos cognitivos para enfrentar situações diversas apoiadas em quatro aspectos (PERRENOUD, 2000, p. 15):

a) as competências não são elas mesmas saberes ou atitudes, mas mobilizam, integram e orquestram tais recursos;

b) essa mobilização só é pertinente em situação, sendo cada situação singular, mesmo que se possa tratá-la em analogia com outras, já encontradas;

c) o exercício da competência passa por operações mentais complexas, subentendidas por esquemas de pensamento que permitem determinar (mais ou menos consciente e rapidamente) e realizar (de modo mais ou menos eficaz) uma ação relativamente adaptada à situação;

d) as competências profissionais constroem-se, em formação, mas também ao sabor da navegação diária de um professor, de uma situação de trabalho a outra.

A avaliação acaba se tornando uma ferramenta muito importante para ambos os lados: de um lado, o professor que consegue ter uma visão mais aprofundada sobre o conhecimento do estudante; e de outro lado, o estudante que deixa de lado o medo de ser avaliado e realizar provas, pois a avaliação não se trata apenas disso, mas um processo avaliativo de todo o conhecimento produzido.

Segundo Perrenoud (1999, p.13), “em todos os casos, a avaliação não é um fim em si. É uma engrenagem no funcionamento didático e, mais globalmente, na seleção e na orientação escolar. Ela serve para controlar o trabalho dos estudantes e, simultaneamente, para gerir os fluxos".

Um professor que não avalia constantemente a ação educativa, no sentido indagativo, investigativo do termo, instala sua docência em verdades absolutas, prémoldadas e terminais (HOFFMANN, 2010, p.15). O objetivo é fazer com que o estudante busque o conhecimento ao invés de ganhar tudo pronto.

As notas e conceitos têm por objetivo registrar os resultados da aprendizagem do aluno por uma determinada escola (LUCKESI, 2000). Eles expressam o testemunho do educador de que aquele estudante foi acompanhado durante o processo de ensino e aprendizagem sob sua responsabilidade. Assim, o registro é necessário. Afinal, nossa memória viva não é capaz de reter tantos dados relativos a um estudante, quanto mais de muitos, e por longos anos. O que ocorreu historicamente é que notas ou conceitos passaram a ser a própria avaliação, o que é uma distorção. Se os registros tiverem por objetivo observar o processo de ensino e aprendizagem de cada 
aluno e sua consequente reorientação, eles subsidiam uma avaliação formativa. Mas, não se esses registros representarem apenas classificações sucessivas do estudante.

A obtenção do diploma até então é vista como uma garantia aos empregadores em potencial que seu portador recebeu uma formação, o que permite contratá-lo sem fazer com que preste novos exames. Porém, a atual sistemática avaliativa e conceitual deixa dúvidas sobre esse posicionamento. Uma forma de certificação análoga funciona também no interior de cada sistema escolar, de um ciclo de estudos ao seguinte, até mesmo entre anos escolares. Isso é mesmo visível, pois não existe o equivalente em um mercado de trabalho, o mercado da orientação permanece contratado pelo sistema educativo.

\section{METODOLOGIA DA PESQUISA}

Para desenvolver o presente estudo realizou-se uma pesquisa exploratória, com base em um estudo de caso de uma escola técnica.Os critérios de escolha do caso a ser estudado, baseia-se nos seguintes aspectos:(a) acessibilidade dos dados; (b)escola técnica que realizou reforma curricular; (c) existência de alunos egressos; (d) alunos egressos que estão atuando no mercado de trabalho local.

A coleta de dados foi realizada através de observações, documentos e entrevistas em profundidade (YIN, 2005) com seis estudantes do curso técnico em móveis e com um gerente de produção de uma empresa moveleira. As observações foram realizadas pelos pesquisadores, durante o período de visita à escola técnica e à empresa.

A utilização da análise de documentos ocorreu a partir da sua disponibilidade durante a coleta de dados. As entrevistas foram realizadas com base em um questionário semi estruturado, que possibilitou coletar dados e informações relacionadas a pesquisa.

Após realizar a coleta de dados, procedeu-se a tabulação dos dados para a análise. A análise dos dados foi realizada com base na análise de conteúdo, através da categorização dos dados (BARDIN, 2002). $\mathrm{Na}$ etapa final da análise realizou-se a triangulação dos dados, coletados com base nas observações, documentos e entrevistas.

\section{RESULTADOS E DISCUSSÕES}

\section{A Escola Técnica}

A Escola Técnica Estadual 25 de Julho, localizada na cidade de Ijuí, no Rio Grande do Sul tem sua história iniciada em 17 de novembro de 1960, com a denominação de Escola de Ensino Técnico Industrial. Ao longo dos últimos 55 anos, essa instituição de ensino recebeu inúmeros alunos e professores, que de alguma forma marcaram sua história.

Atualmente, o quadro funcional conta com 115 professores e 18 funcionários em 
diversos setores. Além disso, conta com aproximadamente 1.200 alunos, de educação básica e educação profissional, provenientes da região noroeste do estado do Rio Grande do Sul.

$\mathrm{Na}$ educação profissional, a escola dispõe dos cursos técnico em eletrotécnica, técnico em mecânica, técnico em informática e técnico em móveis. Além disso, a escola conta com vários laboratórios de informática para a educação básica e profissional, bem como com laboratórios específicos para a área tecnológica de cada curso.

O curso técnico em móveis tem duração de 4 semestres (2 anos), mais um estágio prático de 400 horas a ser realizado e com um relatório de Trabalho de Conclusão de Curso e devendo ser apresentado em até 18 meses após estar APTO em todas as competências curriculares do curso. Desse modo, o técnico em móveis se constitui em um profissional com capacidade de projetar e fabricar móveis e esquadrias em madeira e similares, participa do planejamento e supervisão da produção, projeta melhorias e coordena tecnicamente o processo de produção, executa manutenção em produtos moveleiros.

De acordo com o Projeto Político Pedagógico da escola técnica, a avaliação constitui-se num processo dinâmico e constante de acompanhamento do processo educativo, visando ao aperfeiçoamento e a melhoria qualitativa, em termos de aprendizagem do educando e práticas realizadas pelo educador e pela escola.

A escola realiza, durante e ao final de cada ano letivo, a avaliação de suas ações, considerando os objetivos expressos no Projeto Político Pedagógico, com vistas a diagnosticar elementos interferentes (condições, necessidades, dificuldades) e redimensionar as práticas, visando torná-las mais eficazes.

No Plano Pedagógico de Curso do técnico em móveis, estabelecido em 2011, a avaliação é caracterizada como um processo contínuo e diagnóstico, que indica novos elementos e atividades a serem introduzidas pela ação educativa. Assim, assegura o desenvolvimento do educando e a construção das competências necessárias para o desempenho das funções como técnico em móveis.

Para tanto, os estudantes são avaliados através dos seguintes instrumentos: relatórios de atividades, observações da atuação em práticas propostas, auto avaliação crítica, portfólio do estudante, memorial de desempenho, instrumentos teóricos ou práticos, observações, visitas técnicas, trabalhos individuais e de grupo, seminários, elaboração e execução de projetos, avaliações escritas, orais, teóricas e práticas, entre outros.

Os resultados da avaliação do aproveitamento para os estudantes do curso técnico em móveis são expressos ao final das etapas e ao final do estágio, avaliando 
competências, habilidades e valores.Os resultados do aproveitamento em cada etapa são registrados através das menções "APTO" e "NÃO APTO", após a reunião do Conselho de Classe. O Conselho de Classe configura-se como um fórum essencial de avaliação final da etapa, no qual é realizada a confirmação dos estudantes que se encontram APTOS para cursarem as próximas competências e habilidades.

Os estudos de recuperação são oferecidos de forma concomitante ao desenvolvimento de cada etapa sob forma de retomada e revisão das competências trabalhadas, de atividades extraclasses e aplicação de novos instrumentos de avaliação, que deverão demonstrar o progresso e a melhora significativa na aprendizagem. Assim, as aulas regulares das etapas e das competências a serem retomadas, são presenciais e o aluno deve comparecer a $75 \%$ das atividades desenvolvidas.

A partir do momento em que as disciplinas antes conhecidas por todos foram desmembradas e transformadas em habilidades e competências, torna mais ampla a maneira de avaliação a ser feita. Pois, partindo do ponto do que o estudante precisa dominar, o professor consegue fazer uma melhor avaliação individual de cada um, sendo que o estudante necessita obter domíniodo assunto.

Desta forma, as avaliações na educação profissional estão sendo realizadas a partir dos conceitos APTO ou NÃO APTO, sendo APTO aquele que tiver o desenvolvimento das competências e habilidades propostas no Plano Pedagógico de Curso igual ou superior a $50 \%$, sem maiores distinções no intervalo de 50 a $100 \%$. De um modo geral,observa-se que os professores encontram dificuldades em relação às adaptações necessárias para se adequarem a essa nova sistemática, mas mais do que isso, há um descontentamento dos estudantes no que se refere à conceituação adotada no sistema de avaliação.

Para a Escola Técnica,a avaliação dos estudantes é fundamental, mas também é importante conhecer a percepção dos empresários da área moveleira da região. Assim, torna-se oportuno integrar o sistema de avaliação do curso técnico em móveis com as exigências do mercado de trabalho, a fim de desenvolver as competências e habilidades dos estudantes.

O método de avaliação da aprendizagem pelo currículo baseado nas competências serve para que os professores possam identificar o desempenho e interesse individual dos estudantes durante as atividades propostas. Assim, de acordo com o Plano Pedagógico do Curso e com o Projeto Político Pedagógico da escola, a análise conjunta do método e do perfil do egresso pode auxiliar para alcançar novos padrões de empregabilidade. 


\section{Os estudantes}

Os estudantes entrevistados informaram que conhecem o Plano Pedagógico do Curso técnico em móveis, que foi apresentado durante a aula inaugural e no decorrer do curso.

Nas entrevistas, quatro estudantes informaram que os assuntos abordados em aula e as práticas realizadas durante o curso propiciam aprendizagem suficiente para enfrentar o mercado de trabalho no setor moveleiro. Por outro lado, um aluno mencionou que deveria ter mais atividades práticas e com um maior grau de dificuldade, ao passo que outro aluno comentou que não deveria ter conteúdo teórico e que a duração do curso fosse menor.

Quanto as atividades de avaliação, todos os estudantes consideram adequadas, de acordo com os assuntos e práticas abordadas em aula. Pois, abrangeram o conteúdo de uma forma integral e com direcionamento e tratamento corretos.

Quanto ao sistema de avaliação, 50\% dos estudantes entrevistados disseram estar contentes com o atual sistema de avaliação, ao passo que os outros $50 \%$ se mostraram contrários a esse sistema. Os três estudantes satisfeitos com o sistema avaliativo implantado na Escola Técnica, dois deles usaram expressões do tipo "o que importa é passar", enquanto o outro disse que o que importa é o que ele realmente aprendeu, independentemente da conceituação.

Os três estudantes insatisfeitos com esse sistema alegaram que deveria haver uma maior amplitude de conceitos como forma de instigar os estudantes a buscar algo a mais e tentar ser um estudante destacado também pelo seu conceito avaliativo.

Quanto a motivação das atividades avaliativas, cinco estudantes comentaram que as aulas e as atividades não são motivadoras. Apenas um aluno se sente motivado com as aulas e avaliações, por considerar que as mesmas abrangem tudo o que é necessário.

A justificativa unânime dos estudantes que se mostraram desmotivados com as avaliações foi que há maiores desafios além dos exigidos em aula e que a atual sistemática de avaliação não estimula os estudantes a buscar algo acima da nota mínima exigida.No entanto, um dos alunos afirmou buscar um algo mais por determinação própria, independentemente do conceito avaliativo.

Quando indagados sobre o que é mais importante entre o diploma e a qualificação, quatro estudantes consideraram o diploma e a qualificação de igual importância. Por outro lado, um dos entrevistados disse não se importar com o diploma, somente com o aprendizado, ao passo que o outro afirmou que o diploma é o suficiente para suas aspirações. A justificativa dos estudantes que deram a mesma importância ao diploma e a qualificação foi que ambos são necessários 
para a busca de trabalho. O estudante que deu maior importância ao diploma disse que a partir do momento que tiver o diploma em mãos conseguirá um trabalho e a partir disso aumentará sua empregabilidade. O estudante que se importou mais com a qualificação justificou tal posicionamento por conta de que irá conciliar todas as competências e habilidades do curso e tornar-se um empreendedor do setor moveleiro.

Do total dos entrevistados, três estudantes se julgaram completamente aptos a enfrentar o mercado de trabalho, enquanto os outros três se julgaram parcialmente aptos a enfrentar esse contexto. Os que se julgaram aptos justificaram comentando que as competências e as habilidades são suficientes e foram suficientemente assimiladas. Dois estudantes admitiram não ter o domínio necessário das habilidades propostas para enfrentar o mercado de trabalho e o outro afirmou que mesmo tendo o domínio das competências e habilidades trabalhadas no decorrer do curso, o mesmo não é suficiente para o desempenho ideal de suas pretensões profissionais.

De acordo com as entrevistas realizadas com os alunos, percebeu-se que os a maioria dos alunos conhece o Plano Pedagógico do Curso, mas não está de acordo ou motivado com o atual sistema de avaliação adotado. Constatou-se ainda, que há divergências no que se refere à necessidade $\mathrm{e}$ ao interesse de aprendizagem de acordo com o perfil dos estudantes entrevistados, tendo uma maioria que se contenta com uma aprendizagem básica ou mediana e apenas um aluno que busca um "algo mais".

\section{A empresa}

O gerente de produção entrevistado teve em seu quadro funcional dois estudantes APTOS com diferentes níveis de aprendizagem e, por isso, teve condições de comentar sobre as diferenciações e comportamentos, sendo um estudante com conceituação informal de $50 \quad$ a60\% de aproveitamento e outro com aproveitamento acima de $90 \%$. De acordo com sua percepção é necessário realizar uma divisão de atividades de acordo com a capacidade e a vontade dos alunos.

Segundo o gerente de produção, há quem até tenha capacidade, mas não se interessa na execução de certas atividades, bem como há aquele que se interessa pela execução, mas não possui habilidades suficientes para fazê-las.A evolução depende muito da boa vontade de cada aluno, mas percebe-se que o aluno com um maior índice de aproveitamento é aquele que tem maior iniciativa e capacidade de execução.

O estagiário com menor índice de aproveitamento muitas vezes não tem a disposição necessária para certas atividades e muito menos busca novos desafios. $\mathrm{O}$ estagiário com maior índice não é perfeito, 
mas com certeza possui um comportamento diferenciado para melhor numa perspectiva geral.

Dessa forma, o gerente considera que o sistema de avaliação de habilidades é válido, mas deveria ter uma maior diversidade de conceitos de avaliação para tentar tirar os estudantes da sua comodidade e, também, oferecer um maior parâmetro de aproveitamento dos alunos.

De acordo com a entrevista realizada com o gerente de produção, constatou-se que há uma situação semelhante e ao mesmo tempo decorrente do comportamento em aula e na prática produtiva. O aluno com menor índice de aproveitamento demonstrou menor interesse e iniciativa, situação constatada também em sala de aula, e apresentou maiores dificuldades na execução das atividades propostas. $\mathrm{O}$ estudante com melhor aproveitamento em sala de aula teve maior iniciativa e capacidade de execução aprimorada.

\section{CONCLUSÕES}

O estudo analisou a inserção dos egressos do ensino técnico ao mercado de trabalho, a partir do sistema de avaliação implantado com a reforma curricular. Desse modo, verificou-se a atual situação da educação profissional e de seu sistema de avaliação com base em um estudo de caso de uma escola técnica.
Neste sentido, observou-se que o currículo por competências e habilidades se propõem em desenvolver aptidões necessárias para a inclusão, a transformação e a intervenção crítica dos estudantes no mercado de trabalho. Embora, o Estado esteja implementando políticas públicas com base na reforma curricular, evidencia-se que as ações para uma efetiva educação profissional sejam incipientes e que o atual sistema de avaliação não atende plenamente $\mathrm{o}$ seu propósito.

Os indicadores educacionais são importantes no processo de melhoria do sistema educacional brasileiro, mas torna-se fundamental que a aplicação de métodos e técnicas adequadas para eficiência e eficácia do processo de ensino e aprendizagem. Além disso, a participação e o envolvimento dos profissionais da educação nas discussões para a elaboração de políticas públicas são essenciais para a implementação de novos processos de ensino e aprendizagem.

Desta forma, este estudo contribui para uma reflexão sobre o modelo de educação profissional, especialmente, no que diz respeito ao sistema de avaliação. De tal modo, que as mudanças (e.g., tecnológicas, econômicas, sociais, culturais) que ocorreu no mercado de trabalho sejam absorvidas no processo de ensino e aprendizagem.

O currículo por competências e habilidades deve orientar a educação no preparo de profissionais que atuem em 
conformidade com a necessidade do mercado de trabalho, rompendo, assim, com o modelo pedagógico tradicional de educação e viabilizando um processo de ensino e aprendizagem baseado nas competências com projetos e situações-problemas.

Por outro lado, este estudo contribui com a escola técnica e com a empresa ao descrever um caso que contempla a inserção dos egressos no mercado de trabalho. Tendo em vista,que as escolas técnicas incorporam novas tecnologias, na amplitude da expressão, para o processo de ensino e aprendizagem, o que tem exigido dos profissionais da educação atualização constante e das escolas investimentos em tecnologias.

O sistema de avaliação apresenta uma lacuna na sua estrutura, pois cria dois polos opostos, um classificando estudantes APTOS e outro como estudantes NÃO APTOS. Essa divisão da aptidão desenvolve nos estudantes uma barreira natural, que pode gerar acomodação e desmotivação.

O conceito APTO ou NÃO APTO fornece uma certificação muito ampla, não apresentando informações detalhadas sobre o processo de avaliação das competências e habilidades de cada estudante. Desse modo, percebe-se há necessidade de uma avaliação mais detalhada das capacidades, mas para isso é preciso que o processo de avaliação seja descritivo. Caso contrário, em vez de colaborar pode dificultar a permanência dos egressos nas empresas, trazendo, com isso, uma desvalorização do profissional e/ou do modelo de certificação e da própria escola técnica. A avaliação da aprendizagem deve estar coerente com as demandas do mercado e com as exigências curriculares.

O processo de ensino e aprendizagem deve ser completo, permitindo a empregabilidade do estudante que será formado a partir da inter-relação entre a teoria e a prática presente na escola técnica. Assim, a educação profissional deve ser inovadora para atender o mercado de trabalho, convertendo os conhecimentos, habilidades e atitudes em competências (DURAND, 2000).

O estudo teve como limitação de pesquisa a carência de estudos para possibilitar a comparação de casos similares. Além disso, as entrevistas com professores da escola técnica poderiam contribuir para esclarecer outros aspectos relacionados com o sistema de avaliação e com a reforma curricular.

Contudo, em estudos futuros poderão ser analisados aspectos tais aspectos, ampliando a coleta de dados com os professores. Da mesma forma, sugere-se a realização de estudos longitudinais para acompanhar as mudanças e adaptações decorrentes da evolução do sistema de avaliação e da própria percepção das empresas sobre a qualificação dos profissionais em escola técnicas. 


\section{REFERÊNCIAS}

BARDIN, L. Análise de conteúdo. Lisboa: Edições 70, 2002.

BOWDITCH, J. L.; BUONO, A. F. Elementos de comportamento organizacional. São Paulo: Pioneira Thomson Learning, 2004.

\section{Brasil. Lei $\mathrm{n}^{\circ}$ 11.741, de 16 de julho de}

2008. Altera dispositivos da Lei $n^{0} 9.394$, de 20 de dezembro de 1996, que estabelece as diretrizes e bases da educação nacional, para redimensionar, institucionalizar e integrar as ações da educação profissional técnica de nível médio, da educação de jovens e adultos e da educação profissional e tecnológica. Disponível em:

<http://www.planalto.gov.br/ccivil_03/_Ato2 007-2010/2008/Lei/L11741.htm>. Acesso em: 10 ago. 2015.

Brasil. Lei $\mathrm{n}^{\circ}$ 9.394, de 20 de dezembro de 1996. Estabelece as diretrizes e bases da educação nacional. Disponível em: <http://www.planalto.gov.br/CCIVIL_03/leis/ L9394.htm>.Acesso em: 10 ago. 2015.

CASTELLS, M. A sociedade em rede: a era da informação: economia, sociedade e cultura. 7. ed. São Paulo: Paz e Terra, 2003.

CNE. Conselho Nacional de Educação.

Parecer CNE/CP 009/2001. Disponível em: <http://portal.mec.gov.br/cne/arquivos/pdf/00 9.pdf>. Acesso em: 10 ago. 2015.

DURAND, T. L'alchimie de la compétence. Revue Française de Gestion, n. 127, p. 84102, 2000.

HOFFMANN, J. Avaliação, Mito \& Desafio uma perspectiva construtivista. 40 . ed. Porto Alegre: Mediação, 2010.

LUCKESI, C. C.Entrevista sobre Avaliação da aprendizagem. Disponível em:

$<$ http://www.luckesi.com.br/textos/art_avaliac
ao/art_avaliacao_entrev_jornal_do_Brasil200 0.pdf>. Acesso em: 18 ago. 2015.

PERRENOUD, P. Avaliação: da excelência à regulação das aprendizagens entre duas lógicas. Porto Alegre: Artes Médicas Sul, 1999.

PERRENOUD, P. Pedagogia Diferenciada. Porto Alegre: ArtMed, 2000.

YIN, R. K. Estudo de caso: planejamento e métodos. 3. ed. Porto Alegre: Bookman, 2005 